J Hum Genet. 2016 January ; 61(1): 79-85. doi:10.1038/jhg.2015.78.

\title{
Cardiovascular pharmacogenomics: current status and future directions
}

\author{
Dan M Roden \\ Vanderbilt University School of Medicine, Nashville, TN, USA
}

\begin{abstract}
Drugs are widely used and highly effective in the treatment of heart disease. Nevertheless, in some instances, even drugs effective in a population display lack of efficacy or adverse drug reactions in individual patients, often in an apparently unpredictable fashion. This review summarizes the genomic factors now known to influence variability in responses to widely used cardiovascular drugs such as clopidogrel, warfarin, heparin and statins. Genomic approaches being used to discover new pathways in common cardiovascular diseases and thus potential new targets for drug development are described. Finally, the way in which this new information is likely to be used in an electronic medical record environment is discussed.
\end{abstract}

\section{PHARMACOGENOMICS-BACKGROUND}

It is axiomatic in clinical medicine that every drug treatment produces variable degrees of efficacy and a range of adverse events when a large population is exposed. Reduced efficacy or increased adverse events are a special problem in situations of decreased compliance, misdiagnosis or drug interactions that markedly elevate (or occasionally decrease) the concentration of the drug at a target molecular site of action. By linking variants in genes important for drug action to variable outcomes of drug therapy, pharmacogenomics attempts to improve therapy with available drugs and to point to avenues for new drug development. Initial discoveries in the field described adverse drug effects that clustered in specific families or in specific racial subgroups: hemolysis in African-American soldiers exposed to antimalarials in WWII (subsequently discovered to be related to G6PD deficiency); prolonged paralysis after succinylcholine due to pseudocholinesterase deficiency; or malignant hypothermia after exposure to general anesthesia now recognized to be due to mutations in the skeletal muscle ryanodine release channel encoded by $R Y R 1$. Thus, an initial focus in the field was on 'outlier' populations, and as genotyping and sequencing technologies matured it became clear that such outliers often reflect the presence of single variants with very large effect sizes. With the increasing sophistication of tools to study genomic diversity, the field has incorporated studies of multiple genetic variants, often with smaller individual effect sizes, as determinants of variability to drug response in an

Correspondence: Professor DM Roden, Oates Institute for Experimental Therapeutics, Assistant Vice-Chancellor for Personalized Medicine, Vanderbilt University School of Medicine, 1285 MRB IV, Nashville, TN 37232-0575, USA. dan.roden@ vanderbilt.edu. 
individual or across a population. Further, current analytic methods examining genomic variation often fail to fully explain variability in drug actions. Thus, tools such as transcriptional, proteomic and metabolomic profiling that may incorporate 'downstream' measures of the effects of multiple genes (often interacting in poorly understood ways) or of gene-environment interactions are now being incorporated into studies of variable drug actions.

Drugs used to treat cardiovascular conditions are among the most widely prescribed therapies worldwide. This review will build on recent summaries ${ }^{1,2}$ to describe the current state of knowledge in cardiovascular pharmacogenomics and the directions in which future progress may be made in discovering the basis for variable drug responses and moving those advances to the bedside to improve clinical care.

\section{CLASSES OF GENES MODULATING DRUG ACTION}

Recognizing that drugs exert their effects by interacting with specific molecular targets, it follows that drug action will depend on drug concentration at the site of action, the interaction between drug and target, factors modifying the function of the target and the extent to which the target contributes to whole organ or whole-body pathophysiology. 'Pharmacokinetics' describes the time course of drug delivery to and removal from target and other (for example, plasma) sites, whereas 'pharmacodynamics' refers to the relationship between drug and its molecular, cellular, whole organ and whole-body effects independent of drug concentration. Variants in genes regulating these processes have been implicated as modulators of drug concentrations and drug effects.

Pharmacokinetics are typically analyzed in terms of variables affecting absorption, distribution, metabolism and elimination, each accomplished by specific gene products. ${ }^{3}$ The commonest route of metabolism is initial drug oxidation by specific member(s) of the cytochrome $\mathrm{P} 450$ (CYP) superfamily, and the most commonly implicated enzymes are CYP3A4, CYP2D6, CYP2C9 and CYP2C19. Drugs or metabolites may also be conjugated with methyl, sulfonyl, glucuronyl or acetyl groups by specific transferases, such as catechol$O$-methylatransferase involved in metabolism of endogenous catecholamines or uridine glucuronyl transferase metabolizing bilirubin. Notably, drug metabolites may exert pharmacologic actions and these can be similar to, different from, or more potent than those of a parent drug. For some drugs, such as clopidogrel or codeine, metabolism is required to generate the active metabolites that actually produce pharmacologic effects.

The processes of absorption, distribution and elimination involve movement of drug (or metabolites) across cell membranes and can be passive or active. Just as specific CYPs are involved in metabolism of individual drugs, specific drug transport molecules accomplish drug uptake and/or efflux from specific cells. Examples of drug transport molecules modulating the pharmacokinetics of commonly used drugs include the multi-drug and toxin extrusion proteins 1 and 2 (MATE1 and MATE2), implicated in metformin concentrations and effects; ${ }^{4} S L C O 1 B 1$, encoding the hepatic uptake transporter OAT1B1, which mediates hepatocyte uptake of multiple statins; ;,6 and $A B C B 1$, encoding $P$-glycoprotein, a widely 
expressed drug efflux pump important for bioavailability, central nervous system penetration and biliary elimination of many drugs, such as dabigatran and digoxin., 7,8

The best recognized examples of genetically determined variability in drug action have arisen from studies identifying one gene in which a loss-of-function variant can produce very large effects. One scenario under which this occurs is 'high risk pharmacokinetics', which describes a situation in which drug concentrations are dependent on the normal function of a single-drug metabolism pathway, either for bioactivation (for example, clopidogrel) or for elimination (for example, warfarin). ${ }^{9}$ In this situation, DNA variants (or drug interactions) that reduce function of the pathway can profoundly affect drug concentrations and, in turn, drug effects.

Large effect sizes may also be seen with variants that alter drug interactions with their target molecules. One example is non-synonymous variants in VKORC1, the target for warfarin action described further below. Another is common non-synonymous single-nucleotide polymorphisms (SNPs) in beta-1 and beta-2 adrenergic receptor genes, which modulate response to beta-blockers in cardiovascular therapy and to beta-agonists in asthma. For example, the arginine-variant at the R389G site in $A D R B 1$ was reported to increase agonistmediated increases in contractility compared with receptors with a glycine at position 389 , and to increase survival among heart failure patients treated with bucindolol. ${ }^{10} \mathrm{~A}$ variation on this theme is now increasingly seen in cancer therapy, with drugs targeting specific pathways (often mutant kinases) expressed in the tumor; prescribing such medications in the absence of the target mutation is ineffective. Although examples of large effect sizes have defined the field to date, it is increasingly well-appreciated that variability in drug action may reflect more complex modulation of metabolism, drug-target interactions and overall target function. Analysis of the effects of multiple genetic variants may require very large data sets and may be facilitated by complementary 'omics' data including metabolomic, transcriptomic and proteomic profiling. ${ }^{11}$

\section{SPECIFIC DRUGS AND CLINICAL SETTINGS}

A prominent role for genetic variation is now appreciated for a number of commonly used cardiovascular drugs, including clopidogrel, warfarin, simvastatin and other statins, and each serves as a model for the discovery and implementation aspects of pharmacogenetics. The current state of the art for these agents is briefly described here, followed by other areas in which pharmacogenetics may influence understanding variability in the action of cardiovascular drugs and in using this information clinically.

\section{CLOPIDOGREL}

Although clopidogrel was approved in the late 1990s as an antiplatelet drug, the fact that CYP2C19 function is critical for its bioactivation was first described in $2006 .{ }^{12}$ The minor allele frequency for a common loss-of-function variant in $C Y P 2 C 19$, termed $C Y P 2 C 19 * 2$, is higher among Asians than among Caucasians, varying from $~ 15$ to $~ 30 \%$, and allele frequency for another loss-of-function variant, termed $* 3$, varies from virtually absent in Africans to $\sim 15 \%$ in East Asians. ${ }^{13}$ Resequencing the gene has identified dozens of rare, 
and heretofore uncharacterized, non-synonymous variants. The functional consequences of CYP2C19 variants on clopidogrel's antiplatelet effects are greatest in individuals with lossof-function variants on both $C Y P 2 C 19$ alleles (for example, homozygotes for $C Y 2 C 19 * 2$ ) and intermediate for individuals heterozygous for loss-of-function alleles. Variants that increase CYP2C19 metabolic activity (notably CYP2C19*17) have been associated with increased clopidogrel effect, and some evidence links them to increased bleeding risk. ${ }^{14}$ Analyses of outcomes by genotype in large placebo-controlled trials of clopidogrel action have supported the idea that homozygotes and to perhaps a lesser extent heterozygotes, demonstrate decreased clopidogrel efficacy, notably in acute coronary syndromes. ${ }^{15}$

Evidence for such an effect in other clinical settings, which clopidogrel's antiplatelet effects may be less important is less compelling. ${ }^{16,17}$ A genome-wide association study (GWAS) examining the extent to which clopidogrel-inhibited adenosine diphosphate-induced platelet aggregation in 429 Amish subjects identified a strong signal at the CYP2C19 locus, arising from the $* 2$ allele. ${ }^{18}$ Interestingly, $73 \%$ of the variability in the trait was judged heritable, but only $12 \%$ could be attributed to $C Y P 2 C 19 * 2$. A further $10 \%$ was attributed to clinical variables, such as age and gender, and the remainder of the variability has not been explained. Thus, although the $C Y P 2 C 19 * 2$ allele exerts an unusually large genetic effect, its overall contribution to variability in clopidogrel action is unexpectedly small. No large randomized clinical trial has evaluated a standard approach to clopidogrel prescribing to a genotype-guided one. Some argue that the biologic data are sufficiently compelling that equipoise is lost and genotypes should be routinely incorporated into clopidogrel prescribing while others argue a randomized clinical trial is required. There are obviously major logistic difficulties in mounting a randomized clinical trial targeting $2-3 \%$ of the general population (that is, only those who are homozygotes for the $* 2$ variant). Associations with variants in other genes, such as $A B C B 1^{19}$ or $P O N 1$ (encoding paraoxonase 1$)^{20}$ have been implicated as modulating clopidogrel activity. The PON1 finding was initially described in a very small association study and multiple larger studies have failed to replicate the result. This is probably an example of the dangers of false-positive associations in candidate gene studies when small numbers are evaluated.

\section{WARFARIN}

Warfarin is administered as a racemate, and the more active enantiomer, S-warfarin, is bioinactivated by $C Y P 2 C 9 .{ }^{21}$ Initial studies identified two relatively common nonsynonymous variants in the gene, one termed $* 2$ reducing function and one termed $* 3$ nearly completely eliminating function. In an initial study, individuals receiving steady-state dosages $<3 \mathrm{mg}$ per day were more likely to carry $* 2$ and $* 3$ variants and were more likely to display bleeding complications during chronic therapy; ${ }^{22}$ the latter observation remains unexplained. In 2004, coding region variants in a vitamin $\mathrm{K}$ complex gene termed VKORC1 were identified as the cause of a rare familial syndrome of warfarin resistance, in which very large dosages of the drug produce no anticoagulant effect. ${ }^{23}$ This finding identified the VKORC1 gene product as the molecular target with which warfarin interacts to exert its anticoagulant effect, and common variation in the VKORC1 promoter was subsequently associated with variability in hepatic VKORC1 transcripts and with steady-state warfarin dose requirement: ${ }^{24}$ individuals expressing more VKORC1 required greater warfarin doses. 
These candidate gene findings were mirrored in GWAS, which identified variation at the VKORC1 and CYP2C 9 loci as contributing up to $50 \%$ of the variability in steady-state warfarin dose requirement: ${ }^{25,26}$ conditioning the GWAS analysis on these two loci identified variation in a third gene, $C Y P 4 F 2$, which had been implicated in vitamin $\mathrm{K}$ metabolism and warfarin response. ${ }^{27}$

It is known that subjects of African ancestry require greater dosages of warfarin for anticoagulation at steady-state and this has been attributed to a greater frequency of high activity VKORC1 promoter variants. ${ }^{28}$ CYP2C $9 * 2$ and $* 3$ do occur in subjects of African origin, but at allele frequencies lower than those seen in Caucasians; other variants $(* 6, * 8$ and *11) have been found in African, but not Caucasian subjects. ${ }^{29}$ As with CYP2C19, resequencing the gene in large number of subjects has identified dozens of new rare variants some of which are presumably loss-of-function. Similarly, rare VKORC1 non-synonymous variants have been described that markedly increase warfarin dose requirement; as with other rare variants, these may be enriched in specific ancestral populations. ${ }^{30}$ In addition, a recent GWAS in African-American subjects identified variation near the CYP2C9 locus, but the association was unrelated to any known variant. ${ }^{31}$

Algorithms have been developed that combine clinical features, co-administered interacting drugs such as certain statins or amiodarone, and genetic variation to predict steady-state warfarin dose. In subjects whose steady-state dose is unusually high (> $7 \mathrm{mg}$ per day) or unusually low ( $<3 \mathrm{mg}$ per day) algorithms that incorporate clinical factors plus genetic factors perform better than those incorporating only clinical factors. ${ }^{32}$ In late 2013, the results of three randomized clinical trials asking the question of whether routinely incorporating genetic variant information into initial warfarin dosing would improve time in the therapeutic range during the subsequent 30 or 90 days were published. ${ }^{33-35}$ Two studies compared clinical algorithms to clinical plus genetic algorithms and showed no difference in time in therapeutic range, wherease a third compared a clinical plus genetic algorithm to an empiric (fixed dose) loading algorithm and demonstrated an improvement in time in therapeutic range. Interestingly, the genetic algorithm performed worse than the clinical only algorithm in the one study that included African-Americans and this observation remains unexplained. None of the trials were large enough or lasted long enough to examine clinical outcomes such as recurrent thrombosis or bleeding (the largest trial has 14 major bleeding events in 1015 patients). One more recent study has implicated $C Y P 4 F 2$ variants risk factor for bleeding during long-term (mean > 3 years in 265 cases versus 305 controls) warfarin therapy. ${ }^{36}$ Another study examined candidate polymorphisms in 250 cases with major warfarin-related bleeding and 259 controls without bleeding in BioVU, the Vanderbilt DNA biobank. Most events occurred during long-term (> 30 days) therapy. The $* 3$ variant in CYP2C9 was significantly more common in the group with bleeding $(13.4 \%)$ than in controls $(6.6 \% ; P=0.017)$; the adjusted odds ratio $(\mathrm{OR})$ was 2.05 (95\% confidence interval $1.04,4.04)$.

New antiplatelet drugs such as prasugrel or ticagrelor and new anticoagulant drugs such as dabigatran, apixaban and rivaroxaban have become available as alternatives to clopidogrel and warfarin. The newer drugs do not appear to have this same pharmacogenomic variability as older ones, are currently more expensive, and some are not approved in certain subsets, 
such as the elderly. Thus, the extent to which and the rate at which clopidogrel and warfarin will be supplanted by newer drugs remains to be determined.

\section{HEPARIN-INDUCED THROMBOCYTOPENIA}

Mining BioVU identified 67 cases of this adverse drug reaction and 884 controls, and a GWAS identified a significant association (OR $18.52(6.33-54.23), P=3.18 \times 10^{-9}$ ) with SNPs near the T-cell death-associated gene 8 . These SNPs tag a missense variant in the gene that was associated with PF4/heparin antibody levels and positive PF4/heparin antibodies in non-heparin treated patients (OR 3.09 (1.14-8.13), $P=0.02$ ). In a candidate gene study, SNPs in the HLA-DRA region were also associated with heparin-induced thrombocytopenia (OR $\left.0.25(0.15-0.44), P=2.06 \times 10^{-6}\right) .37$

\section{STATINS}

HMG-CoA reductase inhibitors (statins) are among the most widely prescribed cardiovascular drugs worldwide. Their undisputed efficacy at lowering low-density lipoprotein (LDL) and reducing cardiovascular events has led to their increasing use in cohorts at lower and lower cardiovascular risk. Pharmacogenetic studies of statins have focused on two broad areas: (1) efficacy judged by the extent to which LDL is lowered and, more recently, the extent to which myocardial infarction and other important vascular events are prevented and (2) myotoxicity. Examples are presented here.

Initial studies of efficacy focused on candidate genes, often those associated with baseline lipid abnormalities. An initial study examined 148 SNPs in 10 candidate genes in 1536 subjects receiving pravastatin, and identified two SNPs in the HMG CoA-reductase gene itself as associated with decreased drug efficacy (that is, smaller decreases in LDL). ${ }^{38}$ Another study reported an association between a single relatively rare SNP in the HMG CoA-reductase gene and lipid lowering in 1601 diabetics. ${ }^{39}$ Among the $3.3 \%$ of subjects who carried a single copy of the minor allele, $51 \%$ of patients failed to reach a cholesterol target, compared to $28 \%$ lacking this allele. In another candidate gene study, APOE genotype was strongly associated with the extent to which multiple statins lowered LDL in diabetics. ${ }^{40}$ Another candidate gene study reported that the extent to which simvastatin lowered LDL was modulated by an intronic variant in $C Y P 3 A 4(C Y P 3 A 4 * 22)$ that reduces $C Y P 3 A 4$ function..$^{41}$ In a group of Chinese subjects, a candidate gene study found associations between change in LDL with rosuvastatin and variants in the $A P O E$ locus, the transporter gene $A B C G 2$, the flavin-containing monooxygenase 3 gene and the lipoprotein lipase gene. ${ }^{42}$ A combined analysis of three GWAS in 3932 subjects exposed to simvastatin, pravastatin or atorvastatin suggested that a variant within the calmin (CLMN) gene whose function remains uncertain and a variant in $A P O C 1$ near $A P O E$ modulated lipid lowering. ${ }^{43}$

An initial study of events during statin therapy in 1214 cases of myocardial infarction or stroke and 2686 controls (all subjects received statins) examined the relationship between case-control status and polymorphisms in six candidate genes, chosen because they had been previously implicated as modulators of lipid levels or statin response. Although multiple associations were discovered, the number of observed associations was no greater 
than anticipated by chance. ${ }^{44}$ Another study sought associations between SNPs in antiinflammatory candidate genes in 668 cases of myocardial infarction and 1217 controls without myocardial infarction, all treated with statins. The strongest interaction was with a SNP in ADAMTS1; homozygotes had an OR of 0.10 (95\% CI, 0.03-0.35). ${ }^{45}$ A large study of subjects with diabetes ascertained from electronic medical records found a single SNP in $L P A$ (G allele at rs 10455872) to be a strong predictor of decreased LDL lowering and of cardiac events during treatment, with a $P=1.5 \times 10^{-29}$ in a meta-analysis involving 30467 subjects. The authors concluded that the $15 \%$ of the population carrying the variant were at higher risk of coronary artery disease than non-carriers and that this effect was not altered by statin treatment. ${ }^{40}$

A number of lines of evidence have implicated a common SNP in $S L C O 1 B 1$ as a risk factor for myopathy during statin treatment, notably with high-dose simvastatin. Investigators in the SEARCH consortium performed a GWAS comparing 85 cases of incident myopathy during treatment with simvastatin at high doses ( $80 \mathrm{mg}$ per day) to 90 controls, and identified a single SNP at genome-wide significance, in tight linkage disequilibrium with a known non-synonymous variant resulting in the V174A, and replicated the result in the Heart Protection Study among subjects receiving $40 \mathrm{mg}$ per day simvastatin. ${ }^{46}$ Homozygote carriers of the C-risk allele, $2.1 \%$ of the SEARCH population, were at $\sim 20$-fold increased risk for biochemically proven statin-related myopathy over 5 years treatment (OR 16.9), whereas homozygotes (24.7\%) were at intermediate, approximately fourfold risk. Voora et al. ${ }^{47}$ found that among users of simvastatin or atorvastatin, discontinuation rates were higher among variant carriers, whereas there was no effect among pravastatin users, who experienced little myopathy; the relationship of these findings to the development of myopathy remains uncertain. A study in Chinese subjects suggested that an intronic SNP in SLCO1B1 was also associated with LDL response among Chinese subjects receiving rosuvastatin or simvastatin. ${ }^{48}$ After cerivastatin was withdrawn from the market because of an unusually high incidence of myotoxicity, a candidate gene study and GWAS examining 185 cases and 732 controls found a modest effect of the V174A SNP (OR 1.9) and implicated an intronic variant in the $R Y R 2$ gene, known to mediate calcium release in cardiac, but not skeletal muscle. ${ }^{49}$

\section{ARRHYTHMIA GENOMICS}

A common framework for analyzing risk of drug-induced QT prolongation and risk for torsades de pointes is 'reduced repolarization reserve'. ${ }^{50}$ This idea suggests that repolarization is a complex, redundant and buffered process and that drug-induced long QT syndrome thus reflects multiple 'hits', commonly drug block of the potassium current $I_{\mathrm{Kr}}$, encoded by $\mathrm{KCNH} 2$ (also known as $H E R G$ ), combined with other factors such as hypokalemia, bradycardia and subclinical ion channel mutations. This concept has been supported by case reports and series of patients with clinically inapparent congenital long QT syndrome 'exposed' by drug block. ${ }^{51-55}$ A number of studies have searched for common and rare variants increasing drug-induced long QT syndrome susceptibility. A large candidate gene survey in 176 cases and two groups of controls $(n=1044)$ found that rs1805128, a non-synonymous (D85N) variant in the potassium channel subunit KCNE1 was present in $8.6 \%$ of cases and $1.9-2.9 \%$ of controls (OR 9.0). ${ }^{56}$ A GWAS of 216 cases 
and 771 controls (all Northern European) did not find any signals at genome-wide significance, arguing against a role for common variants in drug-induced long QT syndrome. ${ }^{57}$ In an analysis of exomes from 65 cases and 148 controls, Weeke et al. ${ }^{58}$ found a significant excess of rare variants in KCNE1 and ACN9 among cases; they also reported that $37 \%$ of cases harbored rare potassium channel variants compared with $21 \%$ of controls. Recent studies have suggested an alternate pathway to QT prolongation: decreased PI3Kinase signaling resulting in altered ion channel expression or function (notably druginduced increased 'late' sodium current); ${ }^{59-62}$ The extent to which this pathway modulates arrhythmia susceptibility remains to be determined.

Atrial fibrillation (AF) remains the commonest arrhythmia-requiring therapy, and genomewide approaches have identified common SNPs at $4 \mathrm{q} 25$ as risk factors, ${ }^{63}$ the nearest gene, PITX2, encodes a transcription factor important for left-right cardiac differentiation and development of the 'pulmonary' myocardium, ${ }^{64,65}$ an important site of AF initiation, and is thus a strong candidate. The SNP rs10033464 at the 4q25 locus was found to predict decreased response to antiarrhythmic drug therapy to maintain sinus rhythm in AF (OR 4.7, $P=0.0013) .{ }^{66}$ In addition, carriers of the variant responded better to sodium channel blockers (class I antiarrhythmics), whereas variant carriers responded better to action potential prolonging (class III) drugs. SNPs at the $4 \mathrm{q} 25$ locus also predict recurrent $\mathrm{AF}$ after cardioversion ${ }^{67}$ and AF ablation. ${ }^{68}$ The common R389G variant in ADRB1, encoding the beta-1-adrenrgic receptor, has been associated with an increased likelihood that a rhythm control strategy would be effective in managing AF. If validated, these results could be the foundation for selecting therapeutic strategies and specific drugs in AF stratified by genotype.

\section{GENOMIC APPROACHES TO IDENTIFYING NEW MECHANISMS FOR DRUG ACTION AND NEW TARGETS}

Analyses of proteomic and transcriptional profiles in cell lines exposed to statins have been used to complement genomic approaches in statin myotoxicity. One study reported 247 differentially regulated transcripts in multiple biologic pathways including drug metabolism, fatty-acid metabolism, biometabolism and inflammation. ${ }^{69}$ Another identified six expression quantitative trait loci interacting with simvastatin exposure and one, in GATM, encoding glycine amidinotransferase, was found to be associated with simvastatin myotoxicity in clinical trials. ${ }^{70}$

Studies with PCSK9 that identified gain-of-function variants as a rare cause of familial hypercholesterolemia prompted Cohen et al. ${ }^{71}$ to examine the relationship between loss-offunction PCSK9 variants and heart disease. They identified two variants that encode stop codons at positions 142 and 679 in 85/3363 middle-aged African- Americans in the Atherosclerosis Risk in Communities study, and showed that variant carriers had $28 \%$ lower mean LDL values, and $88 \%$ less coronary artery disease risk over 15 years. ${ }^{72}$ These studies have been interpreted as identifying PCSK9 as a potential drug target in CAD, and two new agents are now being evaluated for marketing after phase 3 trials reported favorable outcomes not only on LDL values but also on coronary events. ${ }^{73,74}$ 
The paradigm of using genetic approaches to link clear loss-of-function variants to desirable clinical outcomes (and thereby identify or validate drug targets) is now being applied more broadly in very large patient cohorts. For example, very rare loss-of-function variants in NPC1L1, encoding the ezetemibe target, were less common in subjects with coronary artery disease (11/29 954, 0.04\%) compared with controls (71 of 83 140, 0.09\%); these results provide evidence supporting the cardioprotective effect of ezetemibe. ${ }^{75}$ Similarly, rare lossof-function variants in $A P O C 3$ have been associated with lower triglyceride levels ${ }^{76,77}$ and, in 110971 subjects, a lower risk of CAD. ${ }^{77}$ These results suggest that triglyceride lowering is a valid cardioprotective strategy.

Recent studies have also highlighted the relationship between metabolomic profiling and gut microbiota. Koeth and colleagues showed that plasma $L$-carnitine, a component of red meat, is metabolized by intestinal microbiota resulting in a proatherogenic molecule, trimethylamine- $N$-oxide (TAMO) ${ }^{78}$ They reported that vegans produce less TAMO than did meat eaters, and that high plasma $L$-carnitine predicted risk for prevalent cardiovascular disease and cardiac events in a cohort of 2595 subjects, but the risk was confined to those who also had high TAMO levels. In mice, $L$-carnitine feeding increased TAMO concentration and this could be abrogated if intestinal microbiota were suppressed. In another study from the same group, TAMO levels were measured in human volunteers after a phosphatidylcholine challenge (hard boiled eggs plus labeled phosphatidylcholine) before and after administration of broad-spectrum antibiotics to suppress intestinal microbiota. ${ }^{79}$ The increase in TAMO after phosphatidylcholine challenge was markedly suppressed after antibiotic treatment and in a population of 4007 subjects undergoing elective coronary angiography, TAMO levels predicted major adverse cardiovascular events over the subsequent 3 years. These data not only suggest novel biomarkers for CAD identification but also suggest the hypothesis that drugs inhibiting TAMO generation could be antiatherogenic.

\section{CLINICAL IMPLEMENTATION OF PHARMACOGENOMICS}

The identification of genetic variants, especially those with large effect sizes, modulating drug effects alleles has raised the prospect of incorporating this information into routine clinical care to improve outcomes by 'personalizing' the choice of drug or drug dose to maximize efficacy and reduce the risk of serious toxicity. One approach is to genotype patients receiving target drugs at the point of care, whereas a second approach 'preemptively' imbeds multiple pharmacogenomic variants in the electronic medical record and provides advanced point of care decision support when a culprit drug is ordered in a patient with known genomic variants. There are considerable obstacles to implementing even well-documented genomic variants into a clinical care using either paradigm: incomplete evidence on appropriate therapeutic responses in patients with genomic variants; variable effect sizes of genetic variants; uncertainty over function of some variants, notably increasingly well-described rare variants in known target genes; logistic issues such as development of decision support or timely delivery of genetic variant information; and provider unfamiliarity with fundamental concepts in genomic medicine. ${ }^{80}$ 
A number of centers are testing a 'preemptive' approach in which multiple genotypes relevant to the action of many drugs are embedded in electronic medical record systems long before the specific drugs such as clopidogrel, warfarin or tacrolimus are prescribed. ${ }^{81-83}$ In addition, the National Human Genome Research Institute's electronic Medical Records and Genomics network is using a targeted sequencing approach to explore the preemptive model in 9000 subjects. ${ }^{84}$ An analysis of the first 10000 subjects participating in Vanderbilt University's PREDICT preemptive pharmacogenetic testing program ${ }^{81}$ highlighted the fact that the vast majority (91\%) of subjects harbored a variant likely to affect the prescribing of one of five target drugs (warfarin, clopidogrel, simvastatin, tacrolimus or thiopurines), and that $\sim 5 \%$ harbored high-risk genotypes such as CYP2C19*2/*2. Another potential application of genomic information is the development of multigenic (or multimarker) risk scores to reclassify individuals and thus better target treatments. For example, an individual with moderate coronary artery disease risk but a high genetic risk score might be a candidate for more aggressive prophylactic treatment; further informing the subject of high risk may modify behaviors. ${ }^{85}$ These large experiments should provide further data on how best to implement genomic medicine in the electronic medical record context.

\section{Acknowledgments}

This study was supported in part by grants from the United States Public Health Service (U01 HG006378 and U19 HL65962).

\section{References}

1. Roden DM, Johnson JA, Kimmel SE, Krauss RM, Medina MW, Shuldiner A, et al. Cardiovascular pharmacogenomics. Circ. Res. 2011; 109:807-820. [PubMed: 21921273]

2. Roden DM, Wilke RA, Kroemer HK, Stein CM. Pharmacogenomics: the genetics of variable drug responses. Circulation. 2011; 123:1661-1670. [PubMed: 21502584]

3. Evans WE, Relling MV. Pharmacogenomics: translating functional genomics into rational therapeutics. Science. 1999; 286:487-491. [PubMed: 10521338]

4. Stocker SL, Morrissey KM, Yee SW, Castro RA, Xu L, Dahlin A, et al. The effect of novel promoter variants in MATE1 and MATE2 on the pharmacokinetics and pharmacodynamics of metformin. Clin. Pharmacol. Ther. 2013; 93:186-194. [PubMed: 23267855]

5. Pasanen MK, Neuvonen M, Neuvonen PJ, Niemi M. SLCO1B1 polymorphism markedly affects the pharmacokinetics of simvastatin acid. Pharmacogenet. Genomics. 2006; 16:873-879. [PubMed: 17108811]

6. Ho RH, Choi L, Lee W, Mayo G, Schwarz UI, Tirona RG, et al. Effect of drug transporter genotypes on pravastatin disposition in European- and African-American participants. Pharmacogenet. Genomics. 2007; 17:647-656. [PubMed: 17622941]

7. Fromm MF, Kim RB, Stein CM, Wilkinson GR, Roden DM. Inhibition of P-glycoprotein-mediated drug transport: a unifying mechanism to explain the interaction between digoxin and quinidine. Circulation. 1999; 99:552-557. [PubMed: 9927403]

8. Zhao Y, Hu ZY. Physiologically based pharmacokinetic modelling and in vivo [I]/Ki accurately predict P-glycoprotein-mediated drug-drug interactions with dabigatran etexilate. Br. J. Pharmacol. 2014; 171:1043-1053. [PubMed: 24283665]

9. Roden DM, Stein CM. Clopidogrel and the concept of high risk pharmacokinetics. Circulation. 2009; 119:2127-2130. [PubMed: 19398674]

10. Liggett SB, Mialet-Perez J, Thaneemit-Chen S, Weber SA, Greene SM, Hodne D, et al. A polymorphism within a conserved \{beta\}1-adrenergic receptor motif alters cardiac function and \{beta\}-blocker response in human heart failure. Proc. Natl Acad. Sci. 2006; 103:11288-11293. [PubMed: 16844790] 
11. Karnes JH, Driest SV, Bowton EA, Weeke PE, Mosley JD, Peterson JF, et al. Using systems approaches to address challenges for clinical implementation of pharmacogenomics. Wiley Interdiscip. Rev. Syst. Biol. Med. 2013; 6:125-135. [PubMed: 24319008]

12. Hulot JS, Bura A, Villard E, Azizi M, Remones V, Goyenvalle C, et al. Cytochrome P450 2 C19 loss-of-function polymorphism is a major determinant of clopidogrel responsiveness in healthy subjects. Blood. 2006; 108:2244-2247. [PubMed: 16772608]

13. Kurose K, Sugiyama E, Saito Y. Population differences in major functional polymorphisms of pharmacokinetics/pharmacodynamics-related genes in Eastern Asians and Europeans: implications in the clinical trials for novel drug development. Drug Metab. Pharmacokinet. 2012; 27:9-54. [PubMed: 22123129]

14. Sibbing D, Stegherr J, Latz W, Koch W, Mehilli J, Dorrler K, et al. Cytochrome P450 2C19 lossof-function polymorphism and stent thrombosis following percutaneous coronary intervention. Eur. Heart. J. 2009; 30:916-922. [PubMed: 19193675]

15. Mega JL, Simon T, Collet JP, Anderson JL, Antman EM, Bliden K, et al. Reduced-function CYP2C19 genotype and risk of adverse clinical outcomes among patients treated with clopidogrel predominantly for PCI: a meta-analysis. JAMA. 2010; 304:1821-1830. [PubMed: 20978260]

16. Holmes MV, Perel P, Shah T, Hingorani AD, Casas JP. CYP2C19 genotype, clopidogrel metabolism, platelet function, and cardiovascular events: a systematic review and meta-analysis. JAMA. 2011; 306:2704-2714. [PubMed: 22203539]

17. Johnson JA, Roden DM, Lesko LJ, Ashley E, Klein TE, Shuldiner AR. Clopidogrel: a case for indication-specific pharmacogenetics. Clin. Pharmacol. Ther. 2012; 91:774-776. [PubMed: 22513313]

18. Shuldiner AR, O'Connell JR, Bliden KP, Gandhi A, Ryan K, Horenstein RB, et al. Association of cytochrome P450 2C19 genotype with the antiplatelet effect and clinical efficacy of clopidogrel therapy. J. Am. Med. Assoc. 2009; 302:849-857.

19. Mega JL, Close SL, Wiviott SD, Shen L, Walker JR, Simon T, et al. Genetic variants in ABCB1 and CYP2C19 and cardiovascular outcomes after treatment with clopidogrel and prasugrel in the TRITON-TIMI 38 trial: a pharmacogenetic analysis. Lancet. 2010; 376:1312-1319. [PubMed: 20801494]

20. Bouman HJ, Schomig E, van Werkum JW, Velder J, Hackeng CM, Hirschhauser C, et al. Paraoxonase-1 is a major determinant of clopidogrel efficacy. Nat. Med. 2011; 17:110-116. [PubMed: 21170047]

21. Rettie AE, Wienkers LC, Gonzalez FJ, Trager WF, Korzekwa KR. Impaired (S)-warfarin metabolism catalysed by the R144C allelic variant of CYP2C9. Pharmacogenetics. 1994; 4:39-42. [PubMed: 8004131]

22. Aithal GP, Day CP, Kesteven PJ, Daly AK. Association of polymorphisms in the cytochrome P450 CYP2C9 with warfarin dose requirement and risk of bleeding complications. Lancet. 1999; 353:717-719. [PubMed: 10073515]

23. Rost S, Fregin A, Ivaskevicius V, Conzelmann E, Hortnagel K, Pelz HJ, et al. Mutations in VKORC1 cause warfarin resistance and multiple coagulation factor deficiency type 2 . Nature. 2004; 427:537-541. [PubMed: 14765194]

24. Rieder MJ, Reiner AP, Gage BF, Nickerson DA, Eby CS, McLeod HL, et al. Effect of VKORC1 haplotypes on transcriptional regulation and warfarin dose. N. Eng. J. Med. 2005; 352:2285-2293.

25. Cooper GM, Johnson JA, Langaee TY, Feng H, Stanaway IB, Schwarz UI, et al. A genome-wide scan for common genetic variants with a large influence on warfarin maintenance dose. Blood. 2008; 112:1022-1027. [PubMed: 18535201]

26. Takeuchi F, McGinnis R, Bourgeois S, Barnes C, Eriksson N, Soranzo N, et al. A genome-wide association study confirms VKORC1, CYP2C9, and CYP4F2 as principal genetic determinants of warfarin dose. PLoS Genet. 2009; 5:e1000433. [PubMed: 19300499]

27. Caldwell MD, Awad T, Johnson JA, Gage BF, Falkowski M, Gardina P, et al. CYP4F2 genetic variant alters required warfarin dose. Blood. 2008; 111:4106-4112. [PubMed: 18250228]

28. Klein TE, Altman RB, Eriksson N, Gage BF, Kimmel SE, et al. International Warfarin Pharmacogenetics, C. Estimation of the warfarin dose with clinical and pharmacogenetic data. N. Engl. J. Med. 2009; 360:753-764. [PubMed: 19228618] 
29. Ramirez AH, Shi Y, Schildcrout JS, Delaney JT, Xu H, Oetjens MT, et al. Predicting warfarin dosage in European-Americans and African-Americans using DNA samples linked to an electronic health record. Pharmacogenomics. 2012; 13:407-418. [PubMed: 22329724]

30. Scott SA, Edelmann L, Kornreich R, Desnick RJ. Warfarin pharmacogenetics: CYP2C9 and VKORC1 genotypes predict different sensitivity and resistance frequencies in the Ashkenazi and Sephardi Jewish populations. Am. J. Hum. Genet. 2008; 82:495-500. [PubMed: 18252229]

31. Perera MA, Cavallari LH, Limdi NA, Gamazon ER, Konkashbaev A, Daneshjou R, et al. Genetic variants associated with warfarin dose in African-American individuals: a genome-wide association study. Lancet. 2013; 382:790-796. [PubMed: 23755828]

32. Klein TE, Altman RB, Eriksson N, Gage BF, Kimmel SE, Lee MT, et al. Estimation of the warfarin dose with clinical and pharmacogenetic data. N. Engl. J. Med. 2009; 360:753-764. [PubMed: 19228618]

33. Kimmel SE, French B, Kasner SE, Johnson JA, Anderson JL, Gage BF, et al. A pharmacogenetic versus a clinical algorithm for Warfarin dosing. N. Engl. J. Med. 2013; 369:2283-2293. [PubMed: 24251361]

34. Pirmohamed M, Burnside G, Eriksson N, Jorgensen AL, Toh CH, Nicholson T, et al. A randomized trial of genotype-guided dosing of Warfarin. N. Engl. J. Med. 2013; 369:2294-2303. [PubMed: 24251363]

35. Verhoef TI, Ragia G, de Boer A, Barallon R, Kolovou G, Kolovou V, et al. A randomized trial of genotype-guided dosing of acenocoumarol and phenprocoumon. N. Engl. J. Med. 2013; 369:23042312. [PubMed: 24251360]

36. Roth JA, Boudreau D, Fujii MM, Farin FM, Rettie AE, Thummel KE, et al. Genetic risk factors for major bleeding in Warfarin patients in a community setting. Clin. Pharmacol. Ther. 2014; 95:636643. [PubMed: 24503627]

37. Karnes JH, Cronin RM, Rollin J, Teumer A, Pouplard C, Schaffer CM, et al. A genome-wide association study of heparin-induced thrombocytopenia using an electronic medical record. Thromb. Hemost. 2014; 113:772-781.

38. Chasman DI, Posada D, Subrahmanyan L, Cook NR, Stanton VP Jr, Ridker PM. Pharmacogenetic study of statin therapy and cholesterol reduction. J. Am. Med. Assoc. 2004; 291:2821-2827.

39. Donnelly LA, Doney AS, Dannfald J, Whitley AL, Lang CC, Morris AD, et al. A paucimorphic variant in the HMG-CoA reductase gene is associated with lipid-lowering response to statin treatment in diabetes: a GoDARTS study. Pharmacogenet. Genomics. 2008; 18:1021-1026. [PubMed: 18815589]

40. Donnelly LA, Palmer CN, Whitley AL, Lang CC, Doney AS, Morris AD, et al. Apolipoprotein E genotypes are associated with lipid-lowering responses to statin treatment in diabetes: a GoDARTS study. Pharmacogenet. Genomics. 2008; 18:279-287. [PubMed: 18334912]

41. Elens L, Becker ML, Haufroid V, Hofman A, Visser LE, Uitterlinden AG, et al. Novel CYP3A4 intron 6 single nucleotide polymorphism is associated with simvastatin-mediated cholesterol reduction in the Rotterdam Study. Pharmacogenet. Genomics. 2011; 21:861-866. [PubMed: 21946898]

42. Hu M, Lui SS, Mak VW, Chu TT, Lee VW, Poon EW, et al. Pharmacogenetic analysis of lipid responses to rosuvastatin in Chinese patients. Pharmacogenet. Genomics. 2010; 20:634-637. [PubMed: 20679960]

43. Barber MJ, Mangravite LM, Hyde CL, Chasman DI, Smith JD, McCarty CA, et al. Genome-wide association of lipid-lowering response to statins in combined study populations. PloS One. 2010; 5:e9763. [PubMed: 20339536]

44. Hindorff LA, Lemaitre RN, Smith NL, Bis JC, Marciante KD, Rice KM, et al. Common genetic variation in six lipid-related and statin-related genes, statin use and risk of incident nonfatal myocardial infarction and stroke. Pharmacogenet. Genomics. 2008; 18:677-682. [PubMed: 18622260]

45. Peters BJ, Rodin AS, Klungel OH, Stricker BH, de Boer A, Maitland-van der Zee AH. Variants of ADAMTS1 modify the effectiveness of statins in reducing the risk of myocardial infarction. Pharmacogenet. Genomics. 2010; 20:766-774. [PubMed: 21037509] 
46. Link E, Parish S, Armitage J, Bowman L, Heath S, Matsuda F, et al. SLCO1B1 variants and statininduced myopathy-a genomewide study. N. Engl. J. Med. 2008; 359:789-799. [PubMed: 18650507]

47. Voora D, Shah SH, Spasojevic I, Ali S, Reed CR, Salisbury BA, et al. The SLCO1B1*5 genetic variant Is associated with statin-induced side effects. J. Am. Coll. Cardiol. 2009; 54:1609-1616. [PubMed: 19833260]

48. Hu M, Mak VW, Tomlinson B. Intronic variants in SLCO1B1 related to statin-induced myopathy are associated with the low-density lipoprotein cholesterol response to statins in Chinese patients with hyperlipidaemia. Pharmacogenet. Genomics. 2012; 22:803-806. [PubMed: 22668755]

49. Marciante KD, Durda JP, Heckbert SR, Lumley T, Rice K, McKnight B, et al. Cerivastatin, genetic variants, and the risk of rhabdomyolysis. Pharmacogenet. Genomics. 2011; 21:280-288. [PubMed: 21386754]

50. Roden DM. Taking the idio out of idiosyncratic_-predicting torsades de pointes. Pacing Clin. Electrophysiol. 1998; 21:1029-1034. [PubMed: 9604234]

51. Donger C, Denjoy I, Berthet M, Neyroud N, Cruaud C, Bennaceur M, et al. KVLQT1 C-terminal missense mutation causes a forme fruste long-QT syndrome. Circulation. 1997; 96:2778-2781. [PubMed: 9386136]

52. Napolitano C, Priori SG, Schwartz PJ, Cantu F, Paganini V, Matteo PS, et al. Identification of a long QT syndrome molecular defect in drug-induced Torsades de Pointes. Circulation. 1997; 96:I211.

53. Paulussen AD, Gilissen RA, Armstrong M, Doevendans PA, Verhasselt P, Smeets HJ, et al. Genetic variations of KCNQ1, KCNH2, SCN5A, KCNE1, and KCNE2 in drug-induced long QT syndrome patients. J. Mol. Med. 2004; 82:182-188. [PubMed: 14760488]

54. Itoh H, Sakaguchi T, Ding WG, Watanabe E, Watanabe I, Nishio Y, et al. Latent genetic backgrounds and molecular pathogenesis in drug-induced long QT syndrome. Circ. Arrhythm. Electrophysiol. 2009; 2:511-523. [PubMed: 19843919]

55. Yang P, Kanki H, Drolet B, Yang T, Wei J, Viswanathan PC, et al. Allelic variants in long QT disease genes in patients with drug-associated Torsades de Pointes. Circulation. 2002; 105:19431948. [PubMed: 11997281]

56. Kääb S, Crawford DC, Sinner MF, Behr ER, Kannankeril PJ, Wilde AAM, et al. A large candidate gene survey identifies the KCNE1 D85N polymorphism as a possible modulator of drug-induced torsades de pointes. Circ. Cardiovasc. Genet. 2011; 5:91-99. [PubMed: 22100668]

57. Behr E, Ritchie MD, Tanaka T, Kääb S, Crawford DC, Nicoletti P, et al. Genome wide analysis of drug-induced Torsades de Pointes: lack of common variants with large effect sizes. PloS One. 2013; 8:e78511. [PubMed: 24223155]

58. Weeke P, Mosley JD, Hanna D, Delaney JT, Shaffer C, Wells QS, et al. Exome sequencing implicates an increased burden of rare potassium channel variants in the risk of drug-induced long QT interval syndrome. J. Am. Coll. Cardiol. 2014; 63:1430-1437. [PubMed: 24561134]

59. Lu Z, Jiang YP, Wu CY, Ballou LM, Liu S, Carpenter ES, et al. Increased persistent sodium current due to decreased PI3K signaling contributes to QT prolongation in the diabetic heart. Diabetes. 2013; 62:4257-4265. [PubMed: 23974924]

60. Lu Z, Wu CY, Jiang YP, Ballou LM, Clausen C, Cohen IS, et al. Suppression of phosphoinositide 3-kinase signaling and alteration of multiple ion currents in drug-induced longQT syndrome. Sci. Transl. Med. 2012; 4:131ra150.

61. Ballou L, Lin R, Cohen I. Contorl of cardiac repolarization by phosphoinositide 3-kinase signaling to ion channels. Circ. Res. 2014; 116:127-137. [PubMed: 25552692]

62. Yang T, Chun YW, Stroud DM, Mosley JD, Knollmann BC, Hong C, et al. Screening for acute IKr block is insufficient to detect torsades de pointes liability: role of late sodium current. Circulation. 2014; 130:224-234. [PubMed: 24895457]

63. Ellinor PT, Lunetta KL, Albert CM, Glazer NL, Ritchie MD, Smith AV, et al. Meta-analysis identifies six new susceptibility loci for atrial fibrillation. Nat. Genet. 2012; 44:670-675. [PubMed: 22544366] 
64. Mommersteeg MTM, Brown NA, Prall OWJ, de Gier-de Vries C, Harvey RP, Moorman AFM, et al. Pitx $2 \mathrm{c}$ and $\mathrm{Nkx} 2-5$ are required for the formation and identity of the pulmonary myocardium. Circ. Res. 2007; 101:902-909. [PubMed: 17823370]

65. Wang J, Klysik E, Sood S, Johnson RL, Wehrens XH, Martin JF. Pitx2 prevents susceptibility to atrial arrhythmias by inhibiting left-sided pacemaker specification. Proc. Natl Acad. Sci. USA. 2010; 107:9753-9758. [PubMed: 20457925]

66. Parvez B, Vaglio J, Rowan S, Muhammad R, Kucera G, Stubblefield T, et al. Symptomatic response to antiarrhythmic drug therapy is modulated by a common single nucleotide polymorphism in atrial fibrillation. J. Am. Coll. Cardiol. 2012; 60:539-545. [PubMed: 22726630]

67. Parvez B, Shoemaker MB, Muhammad R, Richardson R, Jiang L, Blair MA, et al. Common genetic polymorphism at $4 \mathrm{q} 25$ locus predicts atrial fibrillation recurrence after successful cardioversion. Heart Rhythm. 2013; 10:849-855. [PubMed: 23428961]

68. Shoemaker MB, Bollmann A, Lubitz SA, Ueberham L, Saini H, Montgomery J, et al. Common genetic variants and response to atrial fibrillation ablation. Circ. Arrhythm. Electrophysiol. 2015; 8:296-302. [PubMed: 25684755]

69. Cho YE, Moon PG, Lee JE, Singh TS, Kang W, Lee HC, et al. Integrative analysis of proteomic and transcriptomic data for identification of pathways related to simvastatin-induced hepatotoxicity. Proteomics. 2013; 13:1257-1275. [PubMed: 23322611]

70. Mangravite LM, Engelhardt BE, Medina MW, Smith JD, Brown CD, Chasman DI, et al. A statindependent QTL for GATM expression is associated with statin-induced myopathy. Nature. 2013; 502:377-380. [PubMed: 23995691]

71. Cohen J, Pertsemlidis A, Kotowski IK, Graham R, Garcia CK, Hobbs HH. Low LDL cholesterol in individuals of African descent resulting from frequent nonsense mutations in PCSK9. Nat. Genet. 2005; 37:161-165. [PubMed: 15654334]

72. Cohen JC, Boerwinkle E, Mosley TH Jr, Hobbs HH. Sequence variations in PCSK9, low, LDL, and protection against coronary heart disease. N. Engl. J. Med. 2006; 354:1264-1272. [PubMed: 16554528]

73. Robinson JG, Farnier M, Krempf M, Bergeron J, Luc G, Averna M, et al. Efficacy and safety of alirocumab in reducing lipids and cardiovascular events. N. Engl. J. Med. 2015; 372:1489-1499. [PubMed: 25773378]

74. Sabatine MS, Giugliano RP, Wiviott SD, Raal FJ, Blom DJ, Robinson J, et al. Efficacy and safety of evolocumab in reducing lipids and cardiovascular events. N. Engl. J. Med. 2015; 372:15001509. [PubMed: 25773607]

75. Stitziel NO, Won HH, Morrison AC, Peloso GM, Do R, et al. Myocardial Infarction Genetics Consortium, I. Inactivating mutations in NPC1L1 and protection from coronary heart disease. N. Engl. J. Med. 2014; 371:2072-2082. [PubMed: 25390462]

76. Pollin TI, Damcott CM, Shen H, Ott SH, Shelton J, Horenstein RB, et al. A null mutation in human APOC 3 confers a favorable plasma lipid profile and apparent cardioprotection. Science. 2008; 322:1702-1705. [PubMed: 19074352]

77. The TG and HDL Working Group of the Exome Sequencing Project, N.H., Lung, and Blood Institute. Loss-of-function mutations in APOC3, triglycerides, and coronary disease. N. Engl. J. Med. 2014; 371:22-31. [PubMed: 24941081]

78. Koeth RA, Wang Z, Levison BS, Buffa JA, Org E, Sheehy BT, et al. Intestinal microbiota metabolism of L-carnitine, a nutrient in red meat, promotes atherosclerosis. Nat. Med. 2013; 19:576-585. [PubMed: 23563705]

79. Tang WH, Wang Z, Levison BS, Koeth RA, Britt EB, Fu X, et al. Intestinal microbial metabolism of phosphatidylcholine and cardiovascular risk. N. Engl. J. Med. 2013; 368:1575-1584. [PubMed: 23614584]

80. Manolio TA, Chisholm RL, Ozenberger B, Roden DM, Williams MS, Wilson R, et al. Implementing genomic medicine in the clinic: the future is here. Genet. Med. 2013; 15:258-267. [PubMed: 23306799]

81. Pulley JM, Denny JC, Peterson JF, Bernard GR, Vnencak-Jones CL, Ramirez AH, et al. Operational implementation of prospective genotyping for personalized medicine: the design of the VanderbiltPREDICT project. Clin. Pharmacol. Ther. 2012; 92:87-95. [PubMed: 22588608] 
82. Bell GC, Crews KR, Wilkinson MR, Haidar CE, Hicks JK, Baker DK, et al. Development and use of active clinical decision support for preemptive pharmacogenomics. J. Am. Med. Inform. Assoc. 2014; 21:e93-e99. [PubMed: 23978487]

83. Bielinski SJ, Olson JE, Pathak J, Weinshilboum RM, Wang L, Lyke KJ, et al. Preemptive genotyping for personalized medicine: design of the right drug, right dose, right time-using genomic data to individualize treatment protocol. Mayo Clin. Proc. 2014; 89:25-33. [PubMed: 24388019]

84. Rasmussen-Torvik LJ, Stallings SC, Gordon AS, Almoguera B, Basford MA, Bielinski SJ, et al. Design and anticipated outcomes of the eMERGE-PGx project: a multicenter pilot for preemptive pharmacogenomics in electronic health record systems. Clin. Pharmacol. Ther. 2014; 96:482-489. [PubMed: 24960519]

85. Robinson CL, Jouni H, Kruisselbrink TM, Austin EE, Christensen KD, Green RC, et al. Disclosing genetic risk for coronary heart disease: effects on perceived personal control and genetic counseling satisfaction. Clin. Genet. 2015 